\title{
Produção de biomassa e qualidade química de Panicum maximum cv. Tanzânia submetidos a doses de gesso agricola
}

\author{
Biomass production and chemical quality of Panicum maximum cv. \\ Tanzania submitted to doses of agricultural gypsum
}

- Juliano de Bitencourt Zaccaron', Miguelangelo Ziegler Arboitte ${ }^{2}$

\section{RESUMO}

Foram avaliados os efeitos da aplicação de diferentes dosagens de gesso agrícola na produção de biomassa e na qualidade química da forragem Panicum maximum cv. Tanzânia, implantada em neossolo quartzarênico. 0 delineamento experimental utilizado foi o de blocos ao acaso, com três repetições em três blocos. Cada parcela constituiu-se de canteiros com três (3) metros de comprimento e por um metro e meio $(1,5)$ de largura, com espaços de um $(1)$ metro entre si. Os tratamentos foram cinco (5) dosagens de gesso agrícola, 0,0 - 1,5 - 3,0 - 4,5 e 6,0 t ha-1 aplicados em uma única vez. A pastagem foi cortada quando atingiu, na folha, a bandeira de $70 \mathrm{~cm}$ de altura e resíduo de $30 \mathrm{~cm}$ de altura. $O$ gesso agrícola não influenciou significativamente $(P>0,05)$ nas características avaliadas. Os períodos de corte tiveram influência $(P<0,05)$ sobre as variáveis analisadas, sendo o segundo e terceiro corte os que mais produziram biomassa. Nos cortes com maior produção de biomassa de forragem, houve também maior teor de fibra digestível neutra em sua composição, menor teor de proteína bruta e menor porcentagem de nutrientes digestíveis totais

Palavras-chave: Enxofre. Fibra digestível neutra. Nutrientes digestíveis totais. Pastagem. Proteína bruta.

1 Empresa de Pesquisa Agropecuária e Extensão Rural Catarinense - EPAGRI | julianozaccaron@epagri.sc.gov.br 2 Instituto Federal Catarinense - Campus Santa Rosa do Sul | miguelangelo.arboitte@ifc.edu.br 


\section{Produção de biomassa e qualidade química de Panicum maximum cv. Tanzânia submetidos a doses de gesso agrícola \\ Biomass production and chemical quality of Panicum maximum cv. \\ Tanzania submitted to doses of agricultural gypsum}

\section{ABSTRACT}

The effects of applying different gypsum doses on biomass production and on the chemical quality of forage Panicum maximum cv. Tanzania, implemented in quartzarenic neosol (Typic quartzipsamments). The experimental design was a randomized block design, with three replications in three blocks. Each portion consisted of beds with 3 meters in length and 1.5 meters in width, spaced 1 meter apart. The treatments were five (5) doses of agricultural gypsum, $0.0-1.5-3.0-4.5$ and $6.0 \mathrm{t}$ ha- 1 applied in a single time. The pasture was cut when reached $70 \mathrm{~cm}$ in height and it was allowed height of leaving residual $30 \mathrm{~cm}$. The gypsum was not significant $(P>0.05)$ the characteristics evaluated. The cutting periods influenced $(P<0.05)$ on the variables analyzed, with the second and third cut being the ones that produced the most biomass. In the cuts with higher production of forage biomass there was also a higher content of neutral digestible fiber in its composition, lower crude protein content and lower percentage of total nutrients digestible.

Keywords: Sulfur. Neutral digestible fiber. Total nutrients digestible. Pasture. Crude protein.... 


\section{Introdução}

0 Brasil é o quinto maior país do mundo em território, com 8,5 milhões de km2 de extensão, com cerca de $20 \%$ da sua área (174 milhões de hectares) ocupada por pastagens, mantendo $68 \%$ da área do seu território com florestas preservadas. Possui o maior rebanho comercial do mundo, com 209 milhões de cabeças criadas, na sua maioria, a pasto; é o segundo maior produtor de carne bovina e o líder dentre os exportadores, desde 2004 (ABIEC, 2015).

As pastagens são o principal recurso alimentar utilizado para os animais ruminantes nos diferentes sistemas de produção animal no Brasil. Essa realidade é beneficiada pela disponibilidade de recursos naturais como clima, solo e água, que propiciam o desenvolvimento de grande diversidade de espécies forrageiras nos diferentes ecossistemas existentes no país com alta produtividade de pasto de qualidade, além de fatores econômicos (GERON e BRANCHER, 2007).

Os sistemas tradicionais de produção de bovinos na região sul de Santa Catarina, baseados no uso de pastagens, geralmente são de forrageiras pouco produtivas, com baixa qualidade e manejadas inadequadamente. Segundo Sant'anna e Nabinger (2007), os bons resultados alcançados por outros setores agrícolas, como a produção de grãos, pressionam o setor pecuário a aumentar sua produtividade para se tornarem mais competitivos e viáveis economicamente, de modo a garantir a permanência da atividade sem perder espaço no campo.

A produção de bovinos tem grande possibilidade de aumento em produtividade, garantindo sustentabilidade econômica do setor. Alternativas para melhor explorar esse potencial estão no investimento em melhorias nas pastagens, sendo a introdução de novas espécies forrageiras e/ou uso de fertilizante e condicionadores de solo.

A grande maioria das áreas de produção de pastagens destinadas à criação de animais está situada em solos de baixa fertilidade natural e, certamente,apresenta problemas nutricionais que impedem a expressão do máximo vigor produtivo da forrageira e, consequentemente, afeta a produtividade da pecuária local.

Na região do Litoral Sul de Santa Catarina, os solos são, na sua maioria, neossolos quartzarênico (EMBRAPA, 2006), de textura arenosa, com baixos teores de matéria orgânica, os quais são associados a índices de fertilidade naturalmente deficitários. Isso se reflete no baixo potencial de produção de forragem e seu rápido processo de degradação, caso os cuidados de manejo tenham sido inadequados.

0 enxofe é um dos elementos essenciais às plantas, porém, muitas vezes, este é esquecido nas recomendações de adubação de pastagens. Entretanto, o enxofre tem papel importante na constituição de proteínas, transformando o nitrogênio não protéico em proteína, o que estimula 0 crescimento vigoroso das plantas e a formação de sementes. Além disso, aumenta a resistência ao frio e a períodos de seca. De maneira geral, sua deficiência resulta em restrição ao crescimento da planta (CUSTÓDIO et al., 2005).

0 gesso agrícola pode ser ótima possibilidade de reposição do enxofre (S) no solo, pois possui $16 \%$ de $\mathrm{S}$ em sua constituição e também baixo custo. Na agricultura, o gesso agrícola tem sido usado como fonte dos nutrientes, cálcio e enxofre. Pode ser utilizado também para a correção da camada subsuperficial do solo que contenham altos teores de alumínio trocável (Al3+) e/ou baixos teores de cálcio (Ca2+), melhorando a condição do solo para o desenvolvimento radicular das plantas (DIAS, 1992).

Com perspectivas de melhorar as condições para a produção pecuária através da maximização da produtividade das pastagens, o presente trabalho tem por objetivo avaliar os efeitos da aplicação de diferentes dosagens de gesso agrícola na produção de biomassa e sua influência sobre a composição bromatológica de forragem de Panicum maximum cv. Tanzânia em neossolo quartzarênico. 


\section{MATERIAL E MÉTODOS}

0 experimento foi conduzido nas cooredenadas $29^{\circ} 07^{\prime} 46.1^{\prime \prime} \mathrm{S}$ e $49^{\circ} 45^{\prime} 26.1^{\prime \prime} \mathrm{W}$. Para estipular as recomendações de calagem e adubação, foram coletas amostras de solo em junho de 2013 , nas profundidades de $0,0-0,2 \mathrm{~m}, 0,2-0,4 \mathrm{~m}$ e $0,4-0,6 \mathrm{~m}$ e encaminhadas a laboratório para análise básica de seus constituintes, estimando os teores de nutrientes disponiveis no solo, M.O., Al3+, H + Al e pH (Tabela 1).

Quadro 1: Características químicas iniciais do solo na área do experimento.

\begin{tabular}{|c|c|c|c|c|c|c|c|c|c|c|}
\hline \multirow{2}{*}{$\begin{array}{l}\text { Profundidades } \\
(\mathrm{cm})\end{array}$} & $\mathrm{H}+\mathrm{Al}$ & $\mathrm{Al}$ & $\mathrm{Ca}$ & $\mathrm{Mg}$ & $P$ & \multirow{2}{*}{$\begin{array}{l}\mathrm{K} \\
\mathrm{cmol} / \mathrm{dm}^{3}\end{array}$} & \multirow{2}{*}{\begin{tabular}{|l|}
$\mathrm{S}$ \\
$\mathrm{g} / \mathrm{dm}^{3}$ \\
\end{tabular}} & \multirow{2}{*}{$\begin{array}{l}\mathrm{pH} \\
\mathrm{CaCl}_{2}\end{array}$} & \multirow{2}{*}{$\begin{array}{l}\mathrm{pH} \\
\mathrm{SMP}\end{array}$} & \multirow{2}{*}{$\begin{array}{l}\text { M.O. } \\
\text { g/dm³ }\end{array}$} \\
\hline & \multicolumn{5}{|c|}{$\mathrm{mg} / \mathrm{dm}^{3}$} & & & & & \\
\hline $0-20$ & 4,03 & 0,77 & 0,72 & 1,28 & 32,0 & 0,16 & 6,5 & 3,70 & 6,49 & 6,0 \\
\hline $20-40$ & 4,10 & 1,36 & 0,53 & 1,17 & 4,1 & 0,08 & 8,2 & 3,57 & 6,34 & 3,7 \\
\hline $40-60$ & 4,48 & 1,66 & 0,36 & 1,61 & 0,6 & 0,08 & 11,6 & 3,53 & 6,41 & 4,7 \\
\hline
\end{tabular}

Fonte: Elaboração dos próprios autores.

0 delineamento experimental utilizado foi o de blocos inteiramente casualizados, com três repetições e três blocos. Cada parcela foi constituída de canteiros com três (3) metros de comprimento por um metro e meio $(1,5)$ de largura, com espaços de um $(1)$ metro entre si. Os tratamentos foram cinco dosagens de gesso agrícola: 0,0 - 1,5 - 3,0 - 4,5 e 6,0 t hal, aplicado em uma única dose.

0 preparo da área foi realizado dia 03 de setembro de 2013, de modo convencional, com duas arações e gradagens, até a obtenção das condições ideais para o preparo dos canteiros. No ato do preparo do solo, foi incorporado calcário com o objetivo de elevar a saturação por bases a 70\% de acordo com a exigência das pastagem citadas por SBCS (2004). Assim como a adubação de base, o gesso agrícola foi aplicado superficialmente nos canteiros onde estava previsto cada tratamento cinco (5) dias antes da semeadura.

A pastagem utilizada foi o Panicum maximum cv. Tanzânia, semeada a lanço, no dia 17 de outubro de 2013, com densidade de $5 \mathrm{~kg}$ ha-1, aplicando leve compactação da superfície do solo para melhor contato das sementes com a umidade do mesmo e assim otimizar a germinação.

A determinação do momento para a realização das coletas foi estabelecida através da medição com régua da altura das plantas na curvatura da folha a partir do nível do solo. Quando a média geral da área total do experimento apresentou $70 \mathrm{~cm}$, foram realizadas coletas de todas as parcelas, deixando resíduo de $30 \mathrm{~cm}$ em relação ao solo, conforme orientação descrita em EMBRAPA (2013).

0 primeiro corte foi realizado 63 dias após o plantio (18/12/2013), sendo os seguintes efetuados respectivamente: 17 dias após o $1^{\circ}$ corte (03/01/2014); 18 dias após o $2^{\circ}$ corte (20/01/2014); 20 dias após o $3^{\circ}$ corte (08/02/2014); 21 dias após o $4^{\circ}$ corte (28/02/2014); e, 22 dias após 0 $5^{\circ}$ corte (22/03/2014), cortes estes realizados sempre que a média de altura das plantas em área total atingiu os $70 \mathrm{~cm}$ de altura.

De cada parcela, coletaram-se três amostras. Cada amostra foi coletada com 0 auxílio de um quadrado com dimensões de $0,25 \mathrm{~m} 2$, fixada ao acaso sobre a parcela, tendo-se o cuidado de se descartar as bordaduras do canteiro e áreas que não representam o total da parcela. Logo após a coleta, todos os canteiros foram roçados com segadeira manual, deixando o mesmo residual de $30 \mathrm{~cm}$ e retirando-se o material cortado da área.

As parcelas receberam igualmente adubação nitrogenada em cobertura, de acordo com Martha Jr. et al., (2004), na quantidade de 350kg ha-1 de N, dividida em cinco aplicações, logo após cada corte, na forma de nitrato de amônia. 
Após a coleta, as amostras eram acondicionadas em sacos de papel kraft, identificadas e encaminhadas de imediato ao laboratório de bromatologia para serem pesadas em balança com precisão de 0,1g para a determinação da produção de biomassa de forragem verde (MV). Para determinação do teor de biomassa de forragem parcialmente seca (MPS), as amostras foram submetidas à secagem em estufa de ar forçado à temperatura de $65^{\circ} \mathrm{C}$ por, no mínimo, 72 horas e pesadas após a secagem, as amostras foram trituradas em moinho tipo willey com peneira de $1 \mathrm{~mm}$ e submetidas à secagem definitiva em estufa a $105^{\circ} \mathrm{C}$ por, no mínimo, 16 horas para determinação do teor de biomassa de forragem seca (MS) (SILVA e QUEIROZ, 2002).

Para determinação da produção de biomassas de MV e MS em Kg ha-1, os valores foram extrapolados na fórmula: $\mathrm{Kg}$ ha-1 = (peso $\mathrm{kg}$ da forragem presente em $0,25 \mathrm{~m}^{2} \mathrm{X} 40.000$ ).

Para a realização das análises bromatológicas, o conteúdo seco triturado das repetições de cada canteiro, oriundo do mesmo corte, foi unido e homogeneizado para que formasse a amostra a ser analisada quimicamente.

A fração fibra digestível neutra (FDN) foi determinada de acordo com os procedimentos citados por Senger (2008), a fração de proteína bruta foi determinada de acordo com Silva e Queiroz (2002). A concentração de nutrientes digestíveis totais (NDT) foi estimada conforme a equação proposta por Cappelle et al. (2001) em que: NDT = 99,39 - 0,7641. FDN, sendo posteriormente também estimada em (Kg ha-1), utilizando-se a fórmula: NDT (Kg ha-1) = \%NDT / $100 \times$ MS.

Os dados bromatológicos, quanto às doses de gesso agrícola, foram analisados pela ANOVA, utilizando o programa estatístico ASSISTAT. Os períodos dos cortes foram analisados pela ANOVA e submetidos a testes de regressão.

\section{RESULTADOS E DISCUSSÃO}

No experimento, foi testada a interação entre os tratamentos das doses de gesso e os perídos em que ocorreram os cortes da forragem, como esses não apresentarm significância, foram retirados do modelo matemático para realização das análises.

O Panicum maximum cv. Tanzânia submetidos a diferentes doses de gesso agrícola não apresentaram diferenças significativas $(P>0,05)$ quanto à participação de proteína bruta $(P B)$, fibra digestível neutra (FDN) e nutrientes digestíveis totais (NDT) avaliadas, onde o valores médios verificados foram de 14,51\%; 65,32\% e 49,48\%, respectivamente, para PB, FDN e NDT (Tabela 2).

Aplicando diferentes doses de potássio, nitrogênio e enxofre em capim Tanzânia no perído das águas, Costa et al. (2004) também não observaram influência na composição da PB e de FDN, sendo o valor médio de $10,11 \%$ e $65,73 \%$, respectivamente.

Quadro 2: Médias da porcentagem de proteína bruta (PB), fibra digestível neutra (FDN) e de nutrientes digestíveis totais (NDT) de Panicum maximum cv. Tanzânia, em kg ha1 sob diferentes doses de gesso agricola.

\begin{tabular}{|l|l|l|l|}
\hline Doses $\left(\mathrm{T} \mathrm{ha}^{-1}\right)$ & PB\% & FDN\% & NDT\% \\
\hline 0 & 14,32 & 65,50 & 49,34 \\
\hline 1,5 & 14,48 & 65,85 & 49,07 \\
\hline 3,0 & 14,35 & 65,00 & 49,72 \\
\hline 4,5 & 14,83 & 65,51 & 49,34 \\
\hline 6,0 & 14,58 & 64,76 & 49,91 \\
\hline Média & 14,51 & 65,32 & 49,48 \\
\hline
\end{tabular}

* Médias para cada variável na mesma coluna, não diferem $(P>0,05)$ pelo teste Tukey.

Fonte: Elaboração dos próprios autores. 
Considerando os níveis de proteína brutas verifcados de 14,51\%, o Panicum maximum cv. Tanzânia, submetido a diferentes doses de gesso agrícola, apresentou valores considerados bons, uma vez que o nível mínimo exigido para que não ocorra limitações na ingestão voluntária de forragem pelos ruminantes é de $7 \%$ de PB na dieta.

Ao analisar alturas de pastejo em capim Tanzânia, Rego et al. (2003), observaram a média de $16,73 \%$ na lâmina das folhas e 9,5\% de PB nos caules, enquanto que Cano et al. (2004) preditam para a altura de $70 \mathrm{~cm}$ e idade média das folhas de 17,6 dias, o conteúdo de $11,61 \%$ de PB. Trabalhando com diferentes doses de nirogênio e fósforo, Sousa et al. (2010) observaram valores de proteína bruta de 8,6\% nas doses $0 \mathrm{~kg}$ de nitrogênio e fósforo, e valor de até 12,3\% nas doses de $300 \mathrm{~kg}$ de Nitrogênio e $100 \mathrm{~kg}$ de fósforo, respectivamente.

O valor médio observado da FDN foi de 65,32\%, valor acima dos 55 a $60 \%$ relatados por Van Soest (1994) como limitante do consumo de forragens pelos ruminantes. 0 valor observado é próximo aos $65 \%$ realtados por Machado et al. (1998) e aos 69,24\% preditos pela equação proposta por Cano et al. (2004), para estimação do conteúdo de FDN em Panicum maximum cv. Tanzânia, e inferiror aos $74,02 \%$ relatados por Sousa et al. (2010), com plantas cortadas aos 35 dias de idade.

0 teor de FDN na forragem tem relação negativa com a participação de energia (Detmann et al., 2003), sendo assim o valor da concentração de FDN indica, com boa precisão, o nível energético do alimento ou da dieta (Detmann et al., 2003). Usando essa lógica, Cappele et al. (2001) determinaram equações para predição energética nas dietas através da participação da FDN. No presente estudo, a \%NDT não foi influênciada pelas doses de gesso agrícola, apresentando valor médio de 49,48\%, valor inferior aos 52,2 e 53,9\% relatados por Sousa et al. (2010) em Panicum maximum cv. Tanzânia, sem adubação e com doses de $300 \mathrm{~kg}$ de nitrogênio e $100 \mathrm{~kg}$ de fósforo.

As produções da biomassa do Panicum maximum cv. Tanzânia, expressas em massa verde (MV) e massa seca (MS), não foram influênciadas $(P>0,05)$ pelas doses de gesso agrícola (Tabela 3). As produções médias de MV e MS verificadas apresentaram valores de 19.517 e 4.375 kg ha-1, respectivamente.

Quadro 3: Médias da produção em kg ha-1 de biomassa verde (MV) e seca (MS), de proteína bruta (PB) e de nutrientes digestíveis totais (NDT), de Panicum maximum cv. Tanzânia, em kg ha-1 sob diferentes doses de gesso agrícola.

\begin{tabular}{|l|l|l|l|l|}
\hline Doses $\left(\mathrm{T} \mathrm{ha}^{-1}\right)$ & $\mathrm{MV}(\mathrm{kg}$ ha- 1$)$ & $\mathrm{MS}\left(\mathrm{kg} \mathrm{ha}^{-1}\right)$ & $\mathrm{PB} *\left(\mathrm{~kg} \mathrm{ha}^{-1}\right)$ & $\mathrm{NDT}^{*}\left(\mathrm{~kg} \mathrm{ha}^{-1}\right)$ \\
\hline 0 & 20.419 & 4.515 & 642 & 2.234 \\
\hline 1,5 & 19.309 & 4.316 & 616 & 2.123 \\
\hline 3,0 & 19.447 & 4.372 & 622 & 2.178 \\
\hline 4,5 & 19.244 & 4.329 & 637 & 2.137 \\
\hline 6,0 & 19.164 & 4.341 & 624 & 2.168 \\
\hline Média & 19.517 & 4.375 & 628 & 2.168 \\
\hline
\end{tabular}

Médias para cada variável na mesma coluna, não diferem $(P>0,05)$ pelo teste Tukey. ${ }^{*}$ Características seguidas de asterisco apresentam dados estimados.

Fonte: Elaboração dos próprios autores.

Em Panicum maximum cv. Tanzânia, com aplicação de gesso agrícola e outras fontes de enxofre em diferentes doses, Vilela, Martha Jr. e Souza (2009), não observaram diferenças nas produções de massa verde, enquanto que Custódio et al. (2005) constataram que a aplicação de gesso agrícola em Panicum maximum cv. Tanzânia, promoveu aumento da produção de massa de forragem verde, massa de forragem seca e altura de plantas, utilizando doses crescentes de até $3 \mathrm{t}$ ha-1 
A produção de nutrientes digestíveis totais, proteína bruta, energia digestível e energia metabolizável estimadas, produzidas no Panicum maximum cv. Tanzânia, não foi influenciada pelas doses de gesso agrícola.

Analisando os períodos em que foram realizado os cortes Panicum maximum cv. Tanzânia, sob diferentes doses de gesso agricola, os perídos avaliados apresentaram influência na produção de biomassa verde e seca de forma significativa $(P<0,05)$ (Figura 1 a e $1 \mathrm{~b}$ ).

Figura 1 - Produção de biomassa verde (a) e de biomassa seca (b) de Panicum maximum cv. Tanzânia, em kg ha -1 sob diferentes doses de gesso agricola em relação aos períodos de avaliação.

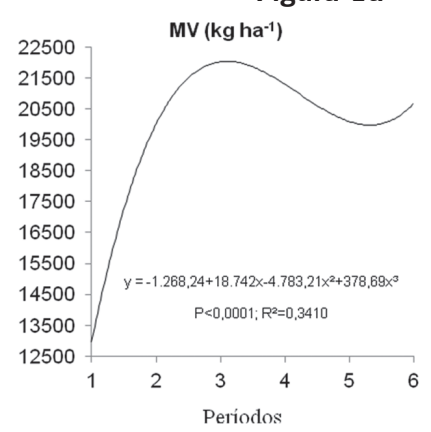
Figura 1 b

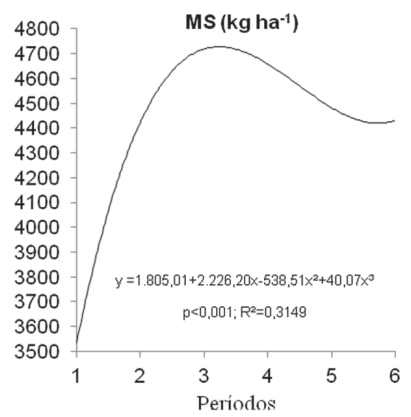

Fonte: Elaboração dos próprios autores.

A produção de biomassa de forragem verde (MV) e de massa seca (MS) apresentou comportamento quadrático, com aumento gradativo nos primeiros três períodos avaliados e, redução, nos posteriores. No primeiro período de avaliação, apresentou o ponto mínimo da curva com a produção média de $12.969 \mathrm{~kg}$ ha-1 de MV e 3.532,8kg ha-1 de MS, chegando à produção màxima no terceiro período avaliado, com produção média de 22.033kg ha-1 de MV e 4.718kg ha-1 de MS.

0 comportamento crescente da produção de massa de forragem nos cortes iniciais se deu pelo gradual desenvolvimento do sistema radicular das plantas, que de início é pequeno, possuindo reduzido acúmulo de reservas, explorando de forma menos eficiente os nutrientes presentes no perfil do solo, e por grande parte do processo fotossintético ser utilizado para emissão de afilhos pela planta, após a realização do primeiro corte, proporcionando aumento da parte aérea até o terceiro corte.

Após a emissão dos afilhos e na medida que as raízes crescem, essas conseguem se aprofundar no solo captando mais água e nutrientes, dando suporte para maior produção de massa de forragem pela planta.

No período referente ao quarto e quinto cortes (datados 08/02/2014 e 28/02/2014, respectivamente), houve déficit hídrico na região, que pode ser observado na Figura 2. Esse déficit, aliado à característica arenosa do solo, causou a queda da produção de massa de forragem verde e seca da planta. Entretanto, antes do último corte, as chuvas se reestabeleceram, fazendo com que a pastagem voltasse a ter incremento na sua produção de massa de forragem, o que ocasionou 0 comportamento quadrático apresentado nas Figuras la e $1 \mathrm{~b}$. 
Figura 2 - Acumulados de chuvas no período do experimento.

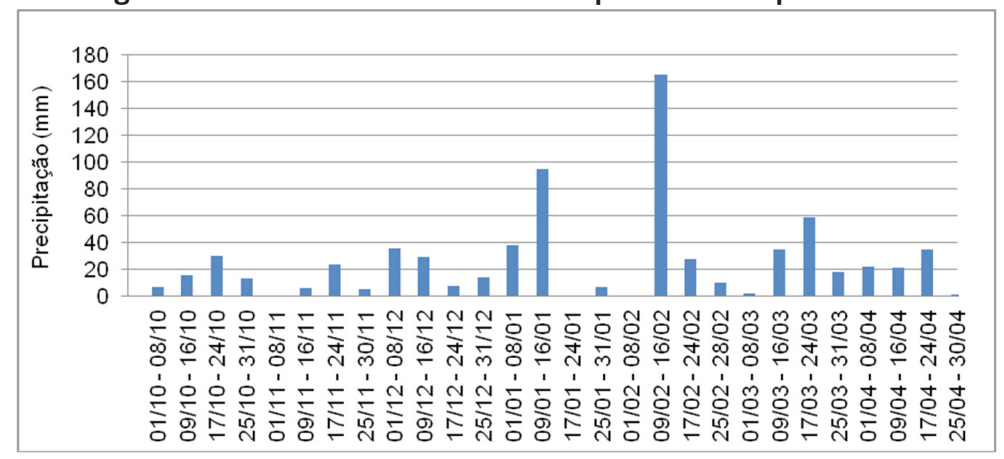

Fonte: Dados da rede do INMET, estação A867 (coordenadas 28,93 S e 48,5 W)

A porcentagem de proteína bruta mostra comportamento diferente do estabelecido pela produção de massa de forragem verde e seca, com pico máximo $(P<0,05)$ nos cortes de menor produção de massa de forragem (Figura 3a). Isso pode ser explicado devido ao fato de que, com maior crescimento da parte aérea da planta, há uma espécie de diluição do $\mathrm{N}$ que dará origem à proteína.

De acordo com Gillet (1984) apud Cunha et al. (2001), mesmo a planta aumentando a absorção de $\mathrm{N}$ do solo, não conseguirá compensar tal diluição, acarretando diminuição na porcentagem de proteína em sua composição. Com esse maior crescimento, há também maior proporção de caule em relação às folhas e os feixes vasculares tornam-se mais desenvolvidos. Essas estruturas possuem mais fibras e menores teores protéicos em sua composição.

Na Figura 3a, pode ser observado o comportamento quadrático na participação da protina na planta. Nesse experimento, o teor médio de PB dos seis cortes foi $14,5 \%$, sendo que o terceiro (de maior produção de massa de forragem) apresentou o menor valor, 11,49\% PB e, no sexto período de avalliação, o maior valor $16,62 \%$. Os valores observados foram melhores que os relatados por Machado et al. (1998), que verificaram o valor de $12 \%$ de PB, enquanto que Costa et al. (2004) verificaram o valor de $11 \%$ de PB em Panicum maximum cv. Tanzânia. Ressalta-se que esses autores ralizaram seus experimentos na região centro-oeste do Brasil, com caracterísiticas edafo-climáticas bem diferentes às do realizado no presente estudo, podendo ter essas influências diretas sob a qualidade da forragem.

Figura 3 - Percentagem de proteína bruta (PB, \%) (a) e de fibra digestível neutra (FDN, \%) (b) de Panicum maximum cv. Tanzânia, em kg ha1 sob diferentes doses de gesso agricola em relação aos períodos de avaliação.

Figura 3a

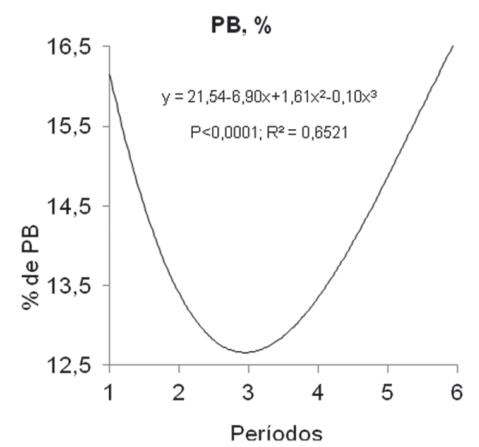

Figura 3b

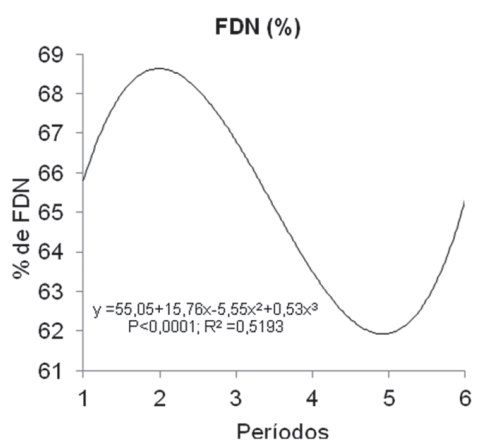

Fonte: Elaboração dos próprios autores

A fração fibra digestível neutra (FDN, \%) (figura 3b) apresentou comportamento quadrático, acompanhando a tendência da produção de biomassa seca (Figura 1b), comportamento esperado, pois esse componente representa entre 50 a $80 \%$ da biomassa da maioria das forrageiras. 0 valor médio apresentado a partir da FDN \%, na forragem estudada, foi de $65,32 \%$, sendo esse valor semelhante 
ao relatado por Costa et al. (2004), que verificaram valor de 65,73\%. Acompanhando a curva de regressão apresentada na figura $3 \mathrm{~b}$, é observado um decréscimo na participação da FDN na planta, nos perídos 3,4 e 5, e aumento no $6^{\circ}$ perído de avaliação, $05^{\circ}$ período avaliado foi onde se obteve o ponto de mínima participação de FDN, no valor de $61,33 \%$. Essa variação da participação da FDN, durante os perídos avaliados, pode ter sido influenciado pela precipitação hídrica ocorrida durante a avaliação, sendo que os perídos de maior precipitação coincidiram com as menores frações de FDN.

Na figura 4, é demosntrada a participação dos Nutrientes Digestíveis Totais (\%NDT), em Panicum maximum cv. Tanzânia, sob diferentes doses de gesso agrícola em relação aos períodos de avaliação

Figura 4 - Percentagem de Nutrientes Digestíveis Totais (NDT, \%) de Panicum maximum cv. Tanzânia, sob diferentes doses de gesso agrícola em relação aos períodos de avaliação.

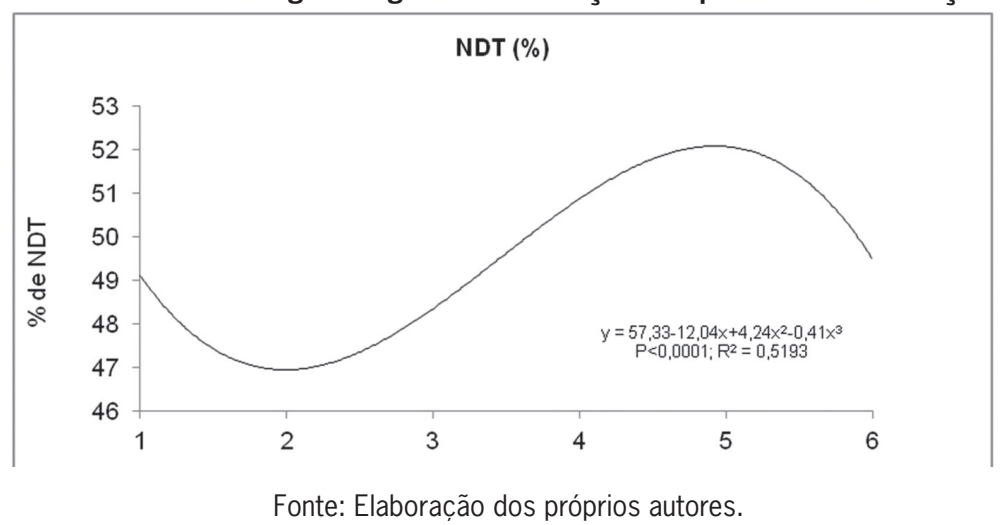

É observado que a partcipação dos NDT é inversamente proporcional à participação da FDN (Figura 3b), enquanto que o NDT representa a parcela digerível do alimento pelo animal. Na fração de fibra digestível neutra, tendo em sua estrutura componentes pouco ou não digeríveis como a lignina, ela irá interferir diretamente na fração NDT. E, quanto maior o teor de FDN na planta, maior será o aporte de componentes não digeríveis pelos animais e, por consequência menor, a fração de NDT.

A média do NDT observada foi de $49,48 \%$, tendo seu ponto mínimo de participação na forragem no $2^{\circ}$ corte $(46,95 \%)$, coincidindo com o período de maior teor de FDN $(69,90 \%)$, enquanto o ponto máximo foi alcançado no $5^{\circ}$ corte (52,08\%), justamente no corte que apresentou menor participação da FDN.

A produção de proteína bruta por hectare apresentou crescimento linear em relação aos perídos avaliados (Figura 5a). Esse componente está intimamente relacionado com a quantidade de biomassa produzida e com a porcentagem de proteína na sua composição.

Analisando os dados obtidos, pode ser observado que, no $1^{\circ}$ corte, a produção de biomassa seca apresentou valor de $3.730,31 \mathrm{~kg}$ ha-1. Esse fator limitou a produção por área de proteína bruta, que foi de 595,62kg ha-1, com níveis médios de $15,96 \%$ PB. No $2^{\circ}$ corte, o incremento de biomassa e da produção de proteína por hectare se manteve estável, com valores de 3,748,09Kg e 530,72kg ha-1, respectivamente.

No $3^{\circ}$ corte, houve incremento na produção de biomassa seca e de proteína por hectare, valores de 5.446,93 e 626,11 kg ha-1, respectivamente, apesar do decréscimo no nível de proteína presente na planta $(11,49 \%)$, a maior produção por hectare de proteína foi compensada pelo maior crescimento da biomassa da forragem.

No $4^{\circ}, 5^{\circ}$ e $6^{\circ}$ cortes, ocorreu declínio na produção de biomassa seca, em que os valores médios verificados foram de 4.553,87; 4.222,40 e 4.545,42kg ha-1, enquanto que a participação de proteína na forragem apresentou aumento gradativo de 14,$16 ; 14,65$ e $16,62 \%$ de PB, respectivamente, 
resultando no aumento da disponibilidade de proteína por hectare, 644,87; 617,91 e 756,21kg ha-1 (figura 5a).

Figura 5 - Produção de proteína bruta estimada por hectare (PB, kg ha-1) (a) e de nutrientes digestíveis totais por hectare (NDT, kg.ha-1) (b) de Panicum maximum cv. Tanzânia, em kg.ha1 sob diferentes doses de gesso agricola em relação aos períodos de avaliação.

Figura $5 a$

Figura 5a

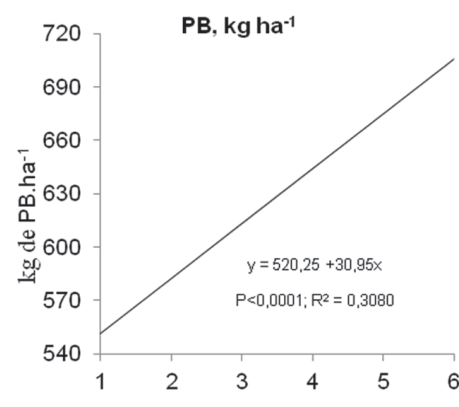

Fonte: Elaboração dos próprios autores.
Figura $5 b$

Figura $5 b$

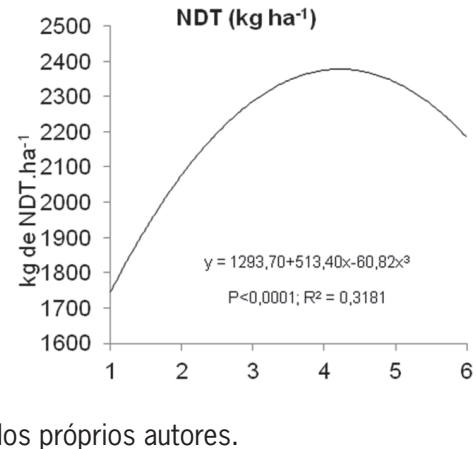

A produção de NDT em kg ha-1, além da relação com a porcentagem de FDN, possui íntima relação com a produção de biomassa de forragem. Isso fez com que sua linha de tendência se comportasse de forma cúbica, com pico máximo de produção por hectare no $3^{\circ}$ corte $(2.705,26$ kg ha-1), coincidindo com o corte que apresentou maior produção de forragem (5.446,93 kg ha-1).

\section{CONCLUSÃO}

O gesso agrícola não interferiu na produção de biomassa de Panicum maximum cv. Tanzânia no primeiro ano de aplicação.A composição química do Panicum maximum cv. Tanzânia foi influenciada pelos períodos de corte. A maior produção de biomassa de forragem coincidiu com o maior teor de FDN em sua composição.

\section{Referências}

ABIEC. Associação Brasileira das Indústrias Exportadoras de Carnes. Pecuária: pecuária brasileira. Disponivel em: <http://www.abiec.com.br/3_pecuaria.asp>. Acesso em: 24 maio 2015.

CANO, C. C. P. et al. Valor nutritivo do capim-Tanzânia (Panicum maximum Jacq. cv. Tanzânia-1) pastejado em diferentes alturas. Rev. Bras. Zootec., Viçosa, v. 33, n. 6, supl. 2, p. 1959-1968, dez. 2004. DOl: http://dx.doi.org/10.1590/S1516-35982004000800006. Disponivel em: <http:// www.scielo.br/scielo.php?script=sci_arttext\&pid=S1516-35982004000800006\&lng=pt\&nrm=iso > . Acessos em: 19 out. 2015.

CAPPELLE, E. R. et al. Estimativas do Valor Energético a partir de Características Químicas e Bromatológicas dos Alimentos. Rev. Bras. Zootec., Viçosa, v. 30, n. 6, p. 1837-1856, dez. 2001. Disponível em <http://www.scielo.br/scielo.php?script=sci_arttext\&pid=S1516-35982001000700022\&lng=pt\& nrm=iso >. Acessos em: 01 maio. 2015. http://dx.doi.org/10.1590/S1516-35982001000700022 
COSTA, K. A. de P. et al. Composição química-bromatológica do capim-Tanzânia em função de doses de nitrogênio, potássio e enxofre. Ciênc. Anim. Bras., Goiânia, v. 5, n. 2, p. 83-91, abr/jun 2004. Disponivel em <https://www.revistas.ufg.br/vet/article/view/324/292>. Acessos em: 02 maio 2015.

CUNHA, M. K. et al. Doses de nitrogênio e enxofre na produção e qualidade da forragem de campo natural de planossolo no Rio Grande do Sul. Rev. Bras. Zootec., Viçosa , v. 30, n. 3, p. 651-658, jun. 2001. DOl: http://dx.doi.org/10.1590/S1516-35982001000300007. Disponível em <http:// www.scielo.br/scielo.php?script=sci_arttext\&pid=S1516-35982001000300007\&lng=pt\&nrm=iso >. Acessos em 10 nov. 2015.

CUSTÓDIO, D. P. et al. O. Avaliação do gesso no desenvolvimento e produção do capim-tanzânia. Ciênc. Anim. Bras., Goiânia, v. 6, n. 1, p. 27-34, jan/mar 2005. Disponível em: <https://www. revistas.ufg.br/vet/article/view/347/322>. Acessos em: 12 jun. 2015.

DETMANN, E. et al. Consumo de fibra em detergente neutro por bovinos em confinamento. Rev. Bras. Zootec., Viçosa, v. 32, n. 6, supl. 1, p. 1763-1777, dez. 2003. DOl: http://dx.doi.org/10.1590/S151635982003000700027. Disponivel em <http://www.scielo.br/scielo.php?script=sci_arttext\&pid=S1516-35982003000700027\&lng=pt\&nrm=iso >. Acessos em 04 abr. 2014.

DIAS, L. E. Uso de gesso como insumo agrícola. Seropédica: EMBRAPA/ Centro de pesquisa de biologia do solo (CNPBS). maio/1992. 6 p. (Comunicado técnico, n.7).

EMBRAPA. Empresa Brasileira de Pesquisa Agropecuária. Centro Nacional de pesquisa de Solos (Rio de Janeiro, RJ). Sistema brasileiro de classificação de solos. 2 ed. Rio de Janeiro, RJ. 2006. 306 p.

EMBRAPA - Empresa Brasileira de Pesquisa Agropecuária; TANZÂNIA: Cultivar de Panicum maximum. Embrapa Gado de Corte - pastagem. Disponível em: <http://www.cnpgc.embrapa.br/produtoseservicos/ pdf/tanzania.pdf>. Acessos em: 01 jul. 2013.

GERON, L. J. V.; BRANCHER, M. A.. Produção de leite a pasto: uma revisão. PUBVET, Londrina, n. 10, v. 1, Ed. 10, 2007. Disponível em: <http://www.pubvet.com.br/artigos_det.asp?artigo=244>. Acessos em: 21 de jun. 2014.

INMET - Instituto Nacional de Meteorologia. Estações automáticas: gráficos. Disponivel em: <http:// www.inmet.gov.br/portal/index.php?r=home/page\&page=rede_estacoes_auto_graf $>$. Acessos em: 14 fev. 2015.

MACHADO, A. O. et al. Avaliação da composição química e digestiva in vitro da matéria seca de cultivares e acessos de Panicum maximum Jacq. Sob duas alturas de corte. Rev. Bras. Zootec., Viçosa, v. 27, n. 5, p. 1057-1063, 1998.

MARTHA JUNIOR, G. B. et al. Intensidade de desfolha e produção de forragem do capim-tanzânia irrigado na primavera e no verão. Pesq. Agropec. Bras., Brasília, v. 39, n. 9, p. 927-936, set. 2004. DOI: http://dx.doi.org/10.1590/S0100-204X2004000900013. Disponível em <http://www. scielo.br/scielo.php?script=sci_arttext\&pid=S0100-204X2004000900013\&lng=pt\&nrm=iso $>$. Acessos em: 13 nov. 2014. 
REGO, F. C. de A. et al. Valor nutritivo do capim-Tanzânia (Panicum maximum Jacq. cv. Tanzânia-1) manejado em alturas de pastejo. Acta Sci. Anim. Sci., Maringá, v. 25, n. 2, p. 363-370, fev. 2003. DOl: http://dx.doi.org/10.4025/actascianimsci.v25i2.205. Disponivel em <http://periodicos. uem.br/ojs/index.php/ActaSciAnimSci/article/view/205/1413>. Acessos em: 11 mai. de 2015.

SANT'ANNA, D. M.; NABINGER, C. Adubação e implantação de forrageiras de inverno em campo nativo. In: SIMPÓSIO DE FORRAGEIRAS E PRODUC̣ÃO ANIMAL, 2, 2007, Porto Alegre. Anais[...]. Porto Alegre: UFRGS, 2007. p. 123-156.

SBCS - Sociedade Brasileira de Ciência do Solo. Comissão de Química e Fertilidade do Solo. Manual de adubação e de calagem para os Estados do Rio Grande do Sul e de Santa Catarina / Sociedade Brasileira de Ciência do Solo. Comissão de Química e Fertilidade do Solo, 10. ed. Porto Alegre, 2004. $400 \mathrm{p}$.

SENGER, C. C. D. et al. Evaluation of autoclave procedures for fiber analysis in forage and concentrate feedstuffs. Anim. Feed Sci. and Tech., v. 146, p. 169-174, 2008. DOI: 10.1016/J.anifeedsci.2007.12.008 Disponivel em: <http://www.scielo.br/scielo.php?script=sci_nlinks\&ref=000097\&pid=S1413-7054201300050001000022\&lng=pt>. Acessos em: 23 ago 2014.

SILVA, D. J.; QUEIROZ, A. C. de. Análise de alimentos (métodos químicos e biológicos). 3. ed. Viçosa: UFV. 2002. 235 p.

SOUSA, R. S. et al . Composição química de capim-tanzânia adubado com nitrogênio e fósforo. Rev. Bras. Zootec., Viçosa, v. 39, n. 6, p. 1200-1205, jun. 2010 . DOl: http://dx.doi.org/10.1590/S151635982010000600006. Disponivel em: <http://www.scielo.br/scielo.php?script=sci_arttext\&pid=S1516$-35982010000600006 \&$ lng=pt\&nrm=iso $>$. acessos em 30 nov. 2015.

VAN SOEST, P. J. Nutitional ecology of the ruminant. Cowallis, 0. \& Books, 1994. 374 p.

VILELA, L.; MARTHA Jr, G. B.; SOUZA, D. M. G. de. Enxofre na produção de Panicum maximum cv. Tanzânia. In: MOSTRA DE RESULTADOS DE PESQUISA DOS PROJETOS FINALIZADOS EM 2006 e 2007, 2.,[Anais...]. Planaltina, DF. Embrapa cerrados, 2009. (Documentos/Embrapa cerrados, 244). 